\title{
Analysis of the influence of recent reforms in China; cardiovascular and cerebrovascular medicines as a case history to provide future direction
}

Zeng $\mathrm{W}^{1}$, Zhen $\mathrm{J}^{1}$, Feng $\mathrm{M}^{1}$, Campbell $\mathrm{SM}^{2,3}$, Finlayson $\mathrm{AE}^{4}$, ${ }^{*}$ Godman $\mathrm{B}^{5,6,7}$

1School of Management, Chongqing Jiaotong University, No.66 Xuefu Road, Nan'an District, Chongqing 400074, China. Email: wenwin99@sina.com; 5411zjj@163.com;

fengmengying@caitu.edu.cn

${ }^{2}$ Centre for Primary Care, Institute of Population Health, University of Manchester, United

Kingdom M13 9PL. Email: stephen.campbell@manchester.ac.uk

${ }^{3}$ NIHR Greater Manchester Primary Care Patient Safety Translational Research Centre, Manchester, M13 9PL, UK

${ }^{4}$ Green Templeton College, 48 Woodstock Road, University of Oxford, Oxford OX2 6HG, UK. Email: alexanderfinlayson@gmail.com

5Department of Laboratory Medicine, Division of Clinical Pharmacology, Karolinska Institutet, Karolinska University Hospital Huddinge, SE-141 86, Stockholm, Sweden. Email:

Brian.Godman@ki.se

${ }^{6}$ Strathclyde Institute of Pharmacy and Biomedical Sciences, University of Strathclyde, Glasgow, UK. Email: Brian.godman@strath.ac.uk

${ }^{7}$ National Institute for Science and Technology on Innovation on Neglected Diseases, Centre for Technological Development in Health, Oswaldo Cruz Foundation (Fiocruz), Rio de Janeiro, Brazil

${ }^{*}$ Author for correspondence

(Accepted for publication in Journal of Comparative Effectiveness Research - Please keep CONFIDENTIAL).

\footnotetext{
Abstract

Background: Pharmaceutical expenditure has grown by $16 \%$ per annum in China, enhanced by incentives for physicians and hospitals. Hospital pharmacies dispense $80 \%$ of medicines in China, accounting for $46 \%$ of total hospital expenditure. Principal measures to moderate drug expenditure growth include pricing initiatives as limited demand-side measures. Objective: Assess current utilization and expenditure including traditional Chinese medicines (TCMs) between 2006 and 2012. Methods: Uncontrolled retrospective study of medicines to treat cardiovascular and cerebrovascular (CV) diseases in one of the largest hospitals in Southwest China. Results: Utilisation increased 3.3 fold for CV medicines, greatest for TCMs, with expenditure increasing 4.85 fold. Low prices for generics were seen, similar to Europe. However, there was variable utilization of generics at $29 \%$ to $31 \%$ of total product volumes in recent years. There continued to be irrationality in prescribing with high use of TCMs, and utilization of medicines dropping significantly once low prices. Conclusion: Prices still have an appreciable impact on utilization in China. Potential measures similar to those implemented among Western European countries could improve rationality and conserve resources.
} 
Key Words: China, Drug utilisation, generics, demand-side measures, cardio-vascular drugs

\section{Background}

There are ongoing initiatives across countries to improve prescribing efficiency. This is due to continual pressure on resources brought about by ageing populations and the continued launch of new premium priced drugs [1-5]. Initiatives for established drugs include multifaceted demand-side measures to increase the prescribing of low costs generics versus originators and patented products in a class [2-8]. Classes include the proton pump inhibitors (PPIs), statins and the renin-angiotensin inhibiting drugs, with the latter including both angiotensin converting enzyme inhibitors (ACEls) and angiotensin receptor blockers (ARBs) [2-7,9-17]. The combination of low-cost generics and mutlifaceted demand-side measures has resulted in considerable savings in some European countries without compromising care $[2-4,7,9,10]$.

As a developing and transitional country, China has also seen rapid growth in pharmaceutical expenditure, with growth averaging 16\% per annum during the past decade [18]. This growth has been enhanced by increasing health insurance coverage, now covering $90 \%$ of the Chinese population [18,19], with the ultimate goal of universal coverage by 2020 [18,20-25]. A number of measures and initiatives have been introduced in China in recent years to try and moderate growth rates to help achieve universal coverage as well as help address the difficulties with seeing physicians and associated costs. These include cutting pharmaceutical prices, introducing essential medicine lists and guidelines and establishing co-payment caps [18-21,24-27]. Having said this, there appear to be currently no universal measures among public insurers to monitor the quality of physician prescribing illustrated for instance by the continued high use of antibiotics and injectables [26, 28-32]. Pharmaceutical expenditure has been a principal target in China since it accounts for $46 \%$ of total hospital expenditure in 2010 [18], with hospital pharmacies dispensing more than $80 \%$ of the country's total medicines [18,26, 27,33]. Out-of-pocket payments account for $36 \%$ of total healthcare expenditure [21]. The principal reasons for the high level of dispensing in hospitals include patient convenience, physician recommendations, the possibility of nonstandardized prescriptions and a greater assurance of pharmaceutical quality [26].

Drug prices are currently determined by the government (state or province) or manufacturers themselves, with actual prices subject to tenders in each province or municipality orchestrated by the local health departments $[18,19,26]$. Since 2006, the margin between the procured and retail price was fixed to approximaely $15 \%$. As a result, greatly standardizing the purchasing channels among Chinese hospitals [19,2627, 33]. For most pharmaceuticals, government control and tendering are the principal forces to decrease prices. Market forces are enhanced by appreciable competition among generic companies, with more than 5,000 pharmaceutical manufacturers in China producing mainly generics [18]. However, there are still no formal pricing mechanisms for generics in China unlike the situation in Europe, which helped achieve generic prices as low as $2 \%$ to $10 \%$ of patent prices in some countries $[2-5,7,14,16]$. The current system in China also encourages physicians to overprescribe pharmaceuticals as well 
as prescribe those that provide the greatest profit to enhance their income. Hospitals also rely on revenues from medicines for their sustainability. This combination subsequently influences prescribing patterns $[18,19,26,32-35]$. Lim and colleagues also found that dispensing doctors prescribed more medicines to patients, and prescribed more originators than generic drugs [36]. This is not helped by similar patient co-payments for an originator or generic. As a result, little increase in the use of generics in China was noted in recent years [18].

Medicines to treat cardiovascular and cerebrovascular diseases are important classes in China due to the increasing incidence and prevalence of these diseases [18]. This includes oxiracetam, which is perceived to improve learning and memory functions of patients with dementia. Jin and colleagues also recently identified cardiovascular drugs among the leading therapeutic classes by volume among hospitals in the Chongqing District of China, alongside anti-infective agents and medicines for the digestive and nervous systems [37], with its population of 28.8 million people (2010 census). This is similar to other districts in China [38]. This also includes over 110 traditional Chinese medicines (TCMs) used to treat these conditions despite increasing awareness of the safety problems associated with TCMs in recent years $[39,40]$. TCMs generally contain yellow pigment from Carthamine or salvianolic acids, and are typically administered via injections. New TCMs continue to be made available with the active components containing for example ginseng, the root of red-rooted salvia, red ginseng, Folium Ginkgo, pseudo-ginseng and Erigeron breviscapus extract. The manufacturers of these typically apply for new medicine approval. As a result, gain exclusive approval for manufacturing which helps obtain higher procurement prices. This use of traditional medicines is despite attempts to develop guidelines and essential medicine lists in China based on published evidence; enhanced by the increased profitability from injections $[18,21,29,31]$.

The prices of cardiovascular drugs have been adjusted four times between 2006 and 2012 in Chongqing District. There were two changes with tendering, in March 2006 and April 2011, and two national adjustments to the maximum retail prices, in January 2007 and March 2011 [41]. However, there are still considerable incentives for physicians to prescribe expensive originators rather than cheaper generics despite initiatives to enhance INN (International Non-proprietary name) prescribing $[18,26,29,33,42]$.

Consequently, the aims of this study are to firstly to assess changes in the utilisation patterns of cardiovascular and cerebrovascular drugs in recent years, including traditional Chinese medicines, with increasing availability of generic drugs. Secondly, assess changes in the utilisation of selected originator and generic cardiovascular and cerebrovascular drugs over time including TCMs as well as potential factors leading to these patterns. Thirdly, assess changes in cardiovascular and cerebrovascular drug expenditure over time as well as changes in the procurement prices for generic, originator drugs and traditional Chinese medicines. This includes the influence of price reductions as well as potentially increasing competition as more generics become available. Lastly, suggest potential future reforms that China could consider to enhance the rational use of medicines as well as obtain further price reductions. 


\section{Methods}

This was an observational uncontrolled retrospective study of prescriptions between 2006 and 2012 [43]. This methodology was chosen since there have been multiple supply- and demand-side measures in China and its various Districts during this period making it difficult to perform an interrupted time series analysis. However where possible, we have performed simple statistical analyses such as the chi-square test.

We will firstly describe why we chose this data set for analysis before describing the methodology chosen for assessing utilisation and expenditure data.

Typically for drug utilisation analyses, data is obtained from health authorities or pharmacy databases [2-7,9,10,12-16]. However in China, most drug utilisation studies are performed with data from hospitals as they incorporate both inpatient and outpatient data [18,39]. In addition, as mentioned, they account for $80 \%$ of total drugs currently dispensed in China $[18,26,33]$. Consequently, hospital procurement data is currently an optimal source of drug utilisation data in China. Accurate data on hospital tendering and procurement is especially important for this type of analysis given the profitability from medicines [29]. This data is not always available from some commercial sources, which can just provide maximum retail price data [33]. In addition, hospitals in China also procure and dispense medicines which are not included in the current reimbursement list. Consequently, comprehensive utilization and expenditure would not be picked up through analyzing reimbursed data sets from the Insurance Department.

Chongqing is a municipality directly under China's central government. In the urban district in Chongqing City, the main public general hospitals include three hospitals affiliated to the Third Military Medical University, two hospitals affiliated to Chongqing Medical University, and 10 municipal hospitals. Every hospital may include different generic drugs, but with the same originator equivalents as part of the tendering process to obtain good prices [18].

We chose the largest hospital in Chongqing District to conduct our study as it is one of the largest hospitals in Southwest China. It can also provide comprehensive datasets on both utilization and expenditure and is a typical health care provider. The dataset was obtained from the magazine company of China Pharmacy. The company is located in Chongqing and is able to collect detailed information from large hospitals in southwest China. The data contains all individual drug information including product names, purchase dates, dosage forms, specification, manufacturers, unit prices and volumes. This is an authoritative source for drug utilisation statistics in China, which is regularly audited. We used a similar approach in previous studies [18].

The datasets are broken down into three groups:

- Originator products. These include products from multinational companies imported into China or manufactured by joint ventures in China founded by multinational pharmaceutical companies. Since these medicines have the original intellectual property and are 
considered by some to have better quality, they typically command a premium prices versus generics

- Generic products. These are produced by enterprises with local investment, including state-owned and private enterprises. Prices are influenced by the Chinese price control policy, and these products typically face competition from a number of different manufacturers. Their quality has improved in recent years with a number of different measures to enhance manufacturing standards. For instance in 2009, all medicines on the Chinese essential medicine list were required to undergo quality sampling and testing at the provincial level at least annually and at the central level at least every three years [21]. Good Manufacturing (GMP) standards were also revised in 2011 to further improve the quality of generic manufacturing in China [21]

- Traditional Chinese medicines. Usually prepared from herbs or other traditional sources, with some preparations involve chemical substances. The main delivery route is via an injection. The characteristics of traditional Chinese medicines are multi target and multi utility. They are believed to provide comprehensive treatment of patients with chronic cardiovascular and cerebrovascular diseases enhanced by a high degree of acceptance among both physicians and patients. They are also believed for instance to improve blood circulation and remove blood stasis and activate collaterals [37].

Volume data was derived from the quantity of drugs dispensed as we considered procurement volume equal to clinical consumption. We chose unit package data as our measurement of utilisation, e.g. one box (e.g., $10 \mathrm{mg} \times 16$ ) or one bottle (e.g., $0.1 \mathrm{~g} \times 1 \mathrm{ml}$ for an injection or $1 \mathrm{~g}$ for powder) as opposed to defined daily doses (DDDs) [44]. This is because:

- there is currently no reliable source for DDDs for traditional Chinese medicines (the principal products used) with several authors using different methodologies and figures in their calculations [39]

- most prescribing physicians in China use the package unit (i.e., one box or one bottle) as the charging unit when calculating their patients' expenditure. This is a similar concept to prescription items in the UK, which is a key metric among UK primary care organisations [16]

- the specifications of the products typically did not change during the study period

Calculations to determine procurement prices, prices per unit and overall expenditure were based on Chinese currency yuan (CNY). There was no allowance for inflation or deflation as we wanted to compute actual changes over time as a result of the tendering process. This is in line with previous studies [2-7,9,10,12-16]. We have also not converted CNY data to either US\$ or Euros during the course of the study as we did not want the pricing data influenced by currency fluctuations, especially during the recent financial crises in Europe and the US.

In addition to overall utilisation and expenditure data, we also analysed several individual products separately to improve our understanding of the situation in China. For this, we typically chose to analyse in detail individual products with an average purchase volume of 1,000 packs per month or a procurement price higher than CNY 20, or a total annual value over CNY 1 million. 


\section{Results}

\section{Utilisation (general)}

Total utilisation of drugs to treat cerebrovascular and cardiovascular diseases increased 3.3 fold between 2006 and 2012, rising from 1.2 million units in 2006 to 3.98 million units in 2012 (Figure 1). This included both single agents and combinations, and was greatest for traditional Chinese medicines at 4.41 fold (Figure 1). Utilisation increased among all product groups apart from ligustrazine. The increase was highest for the statins and the renin-angiotensin inhibiting drugs (Table 1).

Figure 1 - Overall growth in utilisation of the three main categories (by Units) 2006 to 2012 in the Chongqing District

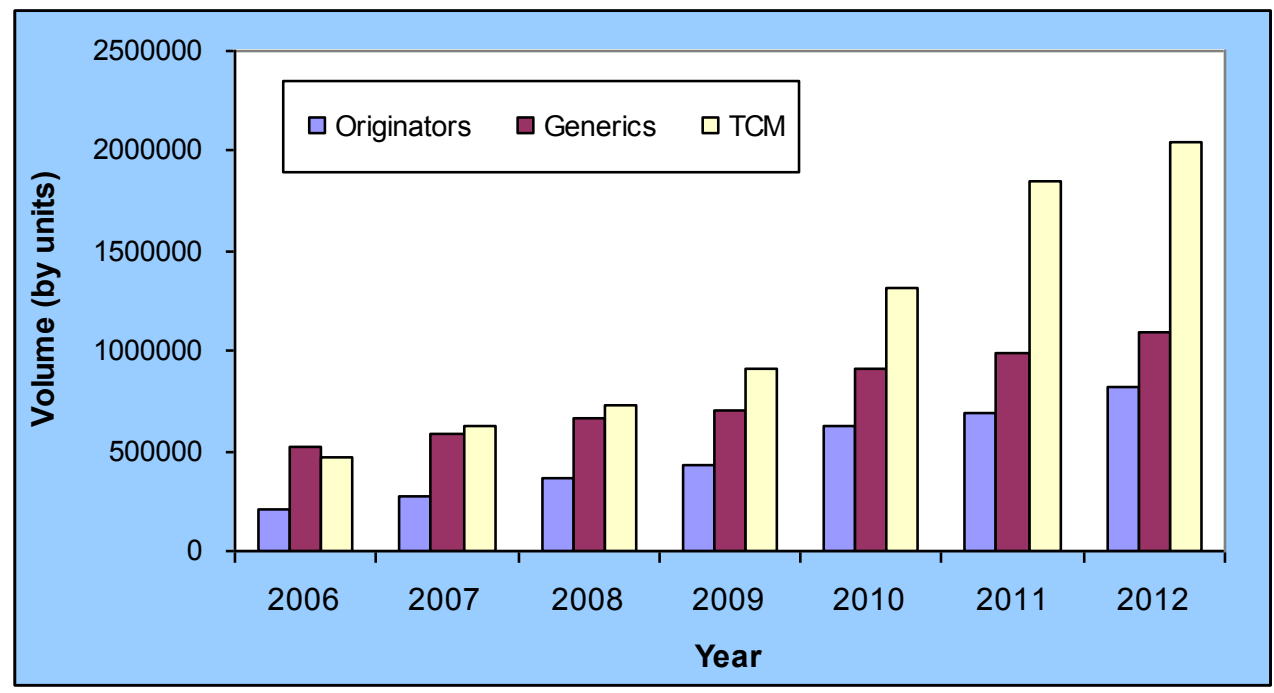

$\underline{\mathrm{TCM}}=$ Traditional Chinese Medicines 
Table 1 - Utilisation of different pharmacotherapeutic groups and traditional Chinese medicines (by unit) in the Chongqing District 2006 to 2012

\begin{tabular}{|c|c|c|c|c|}
\hline \multicolumn{2}{|c|}{ Product/Group } & $\begin{array}{l}\text { Total utilisation } \\
2006\end{array}$ & $\begin{array}{c}\text { Total utilisation } \\
2012\end{array}$ & $\begin{array}{l}\text { Increase }(2012 \\
\text { vs. 2006) }\end{array}$ \\
\hline \multicolumn{2}{|c|}{$\begin{array}{l}\text { Beta blockers (including } \\
\text { combinations) }\end{array}$} & 45253 & 181208 & 4.0 fold \\
\hline \multicolumn{2}{|c|}{$\begin{array}{l}\text { Calcium channel blockers } \\
\text { (including combinations) }\end{array}$} & 66098 & 286700 & 4.34 fold \\
\hline \multirow{2}{*}{$\begin{array}{l}\text { Renin-angiotensin } \\
\text { inhibitor drugs } \\
\text { (including } \\
\text { combinations) }\end{array}$} & ACEls & 51782 & 74665 & 1.44 fold \\
\hline & ARBs & 25662 & 288160 & 11.23 fold \\
\hline \multicolumn{2}{|l|}{ Statins } & 25765 & 214799 & 8.34 fold \\
\hline \multicolumn{2}{|l|}{ Ligustrazine } & 40119 & 0 & 0 \\
\hline \multicolumn{2}{|l|}{ Levocarnitine } & 40874 & 76773 & 1.88 fold \\
\hline \multicolumn{2}{|l|}{ Oxiracetam } & 33390 & 139626 & 4.18 fold \\
\hline \multicolumn{2}{|l|}{ Cinepazide } & 25600 & 36780 & 0.44 fold \\
\hline \multicolumn{2}{|c|}{ Others (consolidated) } & 379869 & 610092 & 1.61 \\
\hline \multicolumn{2}{|c|}{$\begin{array}{l}\text { Total traditional Chinese } \\
\text { medicines }\end{array}$} & 464954 & 2048258 & 4.41 fold \\
\hline \multicolumn{2}{|l|}{ Total } & 1199366 & 3957061 & 3.30 fold \\
\hline
\end{tabular}

NB Ligustrazine is included separately although it may also be considered a Chinese herbal medicine.

Utilisation measured in package units. Fold $=$ times, e.g. 4.0 fold $=4$ times

Analysis of the 12 single products meeting our definition showed an increase in the utilisation of both originators and generics. However, there was variable utilisation of generics with overall utilisation stabilising at $29 \%$ to $31 \%$ of total utilisation for these 12 cardiovascular products in recent years (Table 2. Table $1 \mathrm{~A}$ in the Appendix contains more detailed analysis broken down by 6 month periods). 
Table 2 - Yearly utilisation of both generics and originators for 12 single cardiovascular and cerebrovascular products in the Chongqing District between 2006 to 2012

\begin{tabular}{|l|r|r|r|r|r|r|r|}
\hline \multicolumn{1}{|c|}{ Product } & \multicolumn{1}{l}{2006} & \multicolumn{1}{l}{2007} & \multicolumn{1}{l}{2008} & 2009 & 2010 & 2011 & 2012 \\
\hline Metoprolol - Generic & 0 & 0 & 0 & 0 & 0 & 0 & 0 \\
\hline Metoprolol - Originator & 22637 & 28302 & 33680 & 37920 & 46080 & 64150 & 102240 \\
\hline Bisoprolol - Generic & 0 & 0 & 0 & 0 & 0 & 0 & 0 \\
\hline Bisoprolol - Originator & 8400 & 14040 & 18300 & 17605 & 34380 & 36720 & 40860 \\
\hline Amlodipine - Generic & 9445 & 17170 & 21200 & 34150 & 47570 & 60608 & 66510 \\
\hline Amlodipine - Originator & 7900 & 8900 & 9600 & 19466 & 26200 & 25700 & 41850 \\
\hline Nifedipine - Generic & 25259 & 26128 & 28500 & 28430 & 27100 & 29600 & 17100 \\
\hline Nifedipine - originator & 11880 & 18650 & 31621 & 25380 & 39330 & 37170 & 55620 \\
\hline Felodipine - Generic & 248 & 1120 & 1080 & 1050 & 940 & 250 & 1240 \\
\hline Felodipine - Originator & 2640 & 6670 & 12557 & 19680 & 29844 & 36160 & 53280 \\
\hline Benazepril - Generic & 0 & 329 & 1730 & 3380 & 14810 & 12940 & 15600 \\
\hline Benazepril - Originator & 6480 & 8560 & 11280 & 16560 & 17640 & 25020 & 30899 \\
\hline Losartan - Generic & 0 & 0 & 0 & 0 & 0 & 0 & 4600 \\
\hline Losartan - Originator & 6160 & 10990 & 17800 & 23330 & 38600 & 36200 & 37620 \\
\hline Telmisartan - Generic & 252 & 1500 & 5312 & 5600 & 7600 & 9800 & 11175 \\
\hline Telmisartan - Originator & 1582 & 3587 & 8400 & 8930 & 11600 & 14848 & 26200 \\
\hline Valsartan - Generic & 814 & 1200 & 400 & 1050 & 1200 & 1300 & 1725 \\
\hline Valsartan - Originator & 1766 & 4250 & 14409 & 21030 & 24000 & 40140 & 58880 \\
\hline Atorvastatin - Generic & 7680 & 8400 & 8958 & 11760 & 27659 & 57520 & 89793 \\
\hline Atorvastatin - Originator & 1920 & 2520 & 5339 & 20800 & 31440 & 34160 & 42282 \\
\hline Simvastatin - Generic & 384 & 396 & 2052 & 4716 & 4420 & 3200 & 1680 \\
\hline Simvastatin - Originator & 7210 & 15604 & 31400 & 34320 & 63800 & 60800 & 38600 \\
\hline Irbesartan - Generic & 0 & 700 & 11300 & 18600 & 25735 & 19800 & 25000 \\
\hline Irbesartan - Originator & 6650 & 11500 & 12686 & 20520 & 32920 & 34200 & 43200 \\
\hline
\end{tabular}

Utilisation measured in package units

\section{Procured expenditure (general)}

Total procurement expenditure on cardiovascular and cerebrovascular medicines increased from 30.76million CNY to 149.29 million, a 4.85-fold increase over the 7 years, representing a compounded annual growth rate of $30 \%$ (Figure 2). There was increasing expenditure on traditional Chinese medicines, with their share of total expenditure increasing from $35 \%$ in 2006 to $57 \%$ in 2012 . 
Figure 2 - Total procurement expenditure on cardiovascular and cerebrovascular medicines in CNY in the Chongqing District 2006 to 2012

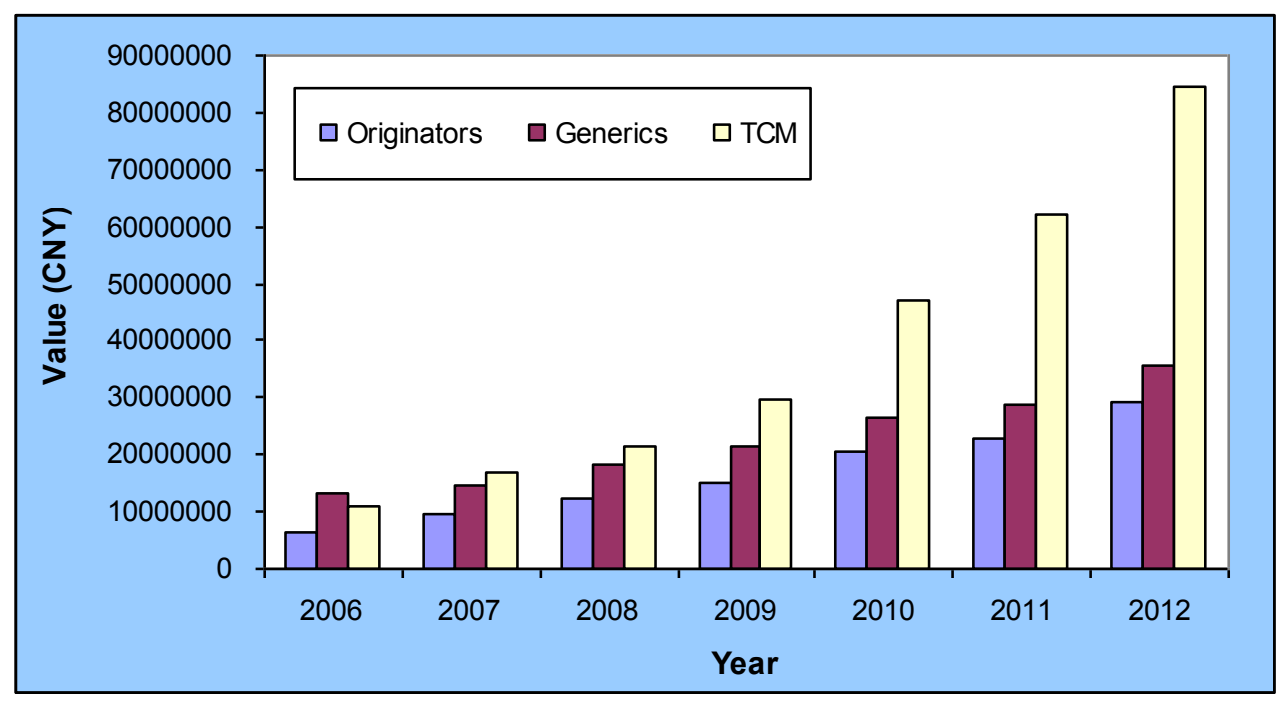

There was also steady growth in procurement expenditure of originator products with procurement values of more than one million CNY in 2012 (Figure 3).

Figure 3 - Total procurement expenditure of the 12 originator cardiovascular and cerebrovascular medicines in CNY in the Chongqing District 2006 to 2012

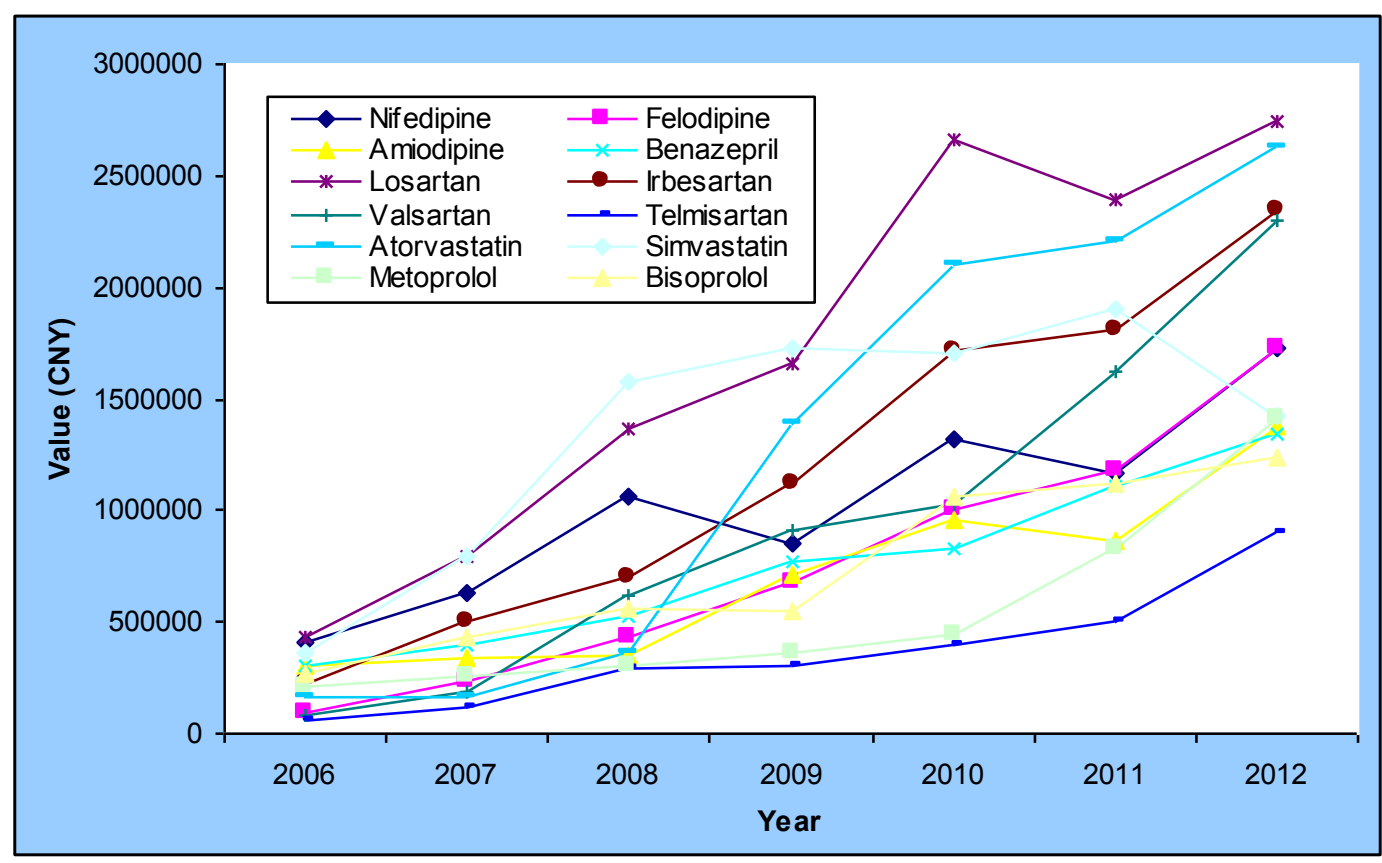

NB. We acknowledge the procurement of telmisartan was less than 1 millionCNY/ year. However, included in view of the rapid rise in recent years

However, there was a mixed picture regarding procurement prices for generics and originators among the principal 12 products over time (Table 3. More detailed analysis in Table $2 \mathrm{~A}$ ). In 
general, procurement prices for both originators and generics decreased over time, although this was not universal.

Table 3 - Change in procurement expenditure/ unit (CNY) for 12 single originator and generic cardiovascular and cerebrovascular drugs in the Chongqing District between 2006 and 2012

\begin{tabular}{|l|r|r|r|r|r|r|l|}
\hline \multicolumn{1}{|c|}{ Product } & \multicolumn{1}{c|}{2006} & \multicolumn{1}{c|}{2007} & \multicolumn{1}{c|}{2008} & 2009 & 2010 & 2011 & 2012 \\
\hline Metoprolol - Generic & & & & & & & \\
\hline Metoprolol - Originator & 9.199 & 9.116 & 8.848 & 9.419 & 9.667 & 12.836 & 13.851 \\
\hline Bisoprolol - Generic & & & & & & & \\
\hline Bisoprolol - Originator & 31.594 & 30.905 & 30.910 & 30.910 & 30.910 & 30.535 & 30.400 \\
\hline Amlodipine - Generic & 32.048 & 35.975 & 36.962 & 37.892 & 38.661 & 38.346 & 38.668 \\
\hline Amlodipine - Originator & 38.372 & 38.047 & 36.780 & 36.763 & 36.372 & 33.479 & 32.929 \\
\hline Nifedipine - Generic & 18.783 & 15.043 & 14.069 & 14.245 & 14.681 & 13.200 & 12.894 \\
\hline Nifedipine - originator & 34.385 & 34.018 & 33.500 & 33.500 & 33.476 & 31.256 & 31.130 \\
\hline Felodipine - Generic & 25.441 & 25.855 & 25.390 & 25.390 & 25.390 & 28.306 & 35.290 \\
\hline Felodipine - Originator & 36.120 & 34.569 & 34.153 & 34.137 & 33.787 & 32.690 & 32.500 \\
\hline Benazepril - Generic & & 35.700 & 35.700 & 35.700 & 35.700 & 30.662 & 29.220 \\
\hline Benazepril - Originator & 47.508 & 46.830 & 46.830 & 46.830 & 46.830 & 44.529 & 43.633 \\
\hline Losartan - Generic & & & & & & & 66.080 \\
\hline Losartan - Originator & 48.764 & 49.210 & 48.289 & 49.148 & 48.874 & 46.352 & 47.802 \\
\hline Telmisartan - Generic & 22.670 & 35.924 & 35.220 & 35.220 & 35.220 & 24.399 & 20.710 \\
\hline Telmisartan - Originator & 34.691 & 34.150 & 34.150 & 34.150 & 34.150 & 34.150 & 34.150 \\
\hline Valsartan - Generic & 20.478 & 19.840 & 19.840 & 19.840 & 19.840 & 16.886 & 16.000 \\
\hline Valsartan - Originator & 43.727 & 43.626 & 42.780 & 42.780 & 42.780 & 40.325 & 39.096 \\
\hline Atorvastatin - Generic & 34.148 & 30.789 & 30.090 & 30.090 & 31.175 & 28.938 & 28.964 \\
\hline Atorvastatin - Originator & 67.269 & 67.000 & 67.009 & 67.000 & 67.000 & 64.541 & 62.240 \\
\hline Simvastatin - Generic & 27.910 & 24.943 & 24.090 & 23.851 & 20.867 & 13.740 & 11.846 \\
\hline Simvastatin - Originator & 50.711 & 50.687 & 50.300 & 50.300 & 26.683 & 31.378 & 36.810 \\
\hline Irbesartan - Generic & & 22.960 & 22.950 & 22.950 & 22.950 & 19.271 & 18.340 \\
\hline Irbesartan - Originator & 31.935 & 31.423 & 31.259 & 31.260 & 31.260 & 31.260 & 31.260 \\
\hline
\end{tabular}

\section{Specific classes and products}

\section{$\beta$ - Adrenergic receptor blockers}

Nogenerics were procured for either of the two higher volume beta blockers over time (Table 2).

There was an increase in the utilisation of esmolol hydrochloride injections during part of the study period. The main esmolol injection was launched in July 2006 with a specification of 0.1 $\mathrm{g} \times 1 \mathrm{ml}$ priced $62.80 \mathrm{CNY}$ per bottle. Only a limited amount was used: 788 bottles in 2006 and 1,685 in 2007 (Figure 4). In April 2008 after the specification was adjusted to $0.2 \mathrm{~g} \times 2 \mathrm{ml}$ with a higher price of 116.52CNY, the procurement volume increased from 5,600 bottles in the first half of 2008 to 21,000 bottles in the first and second half of 2009. After its price decreased to 68.84CNY per bottle, consumption decreased. This reduced to 1,150 bottles in the second half 
of 2012 , a $94.5 \%$ decrease from the peak. Concurrently, the utilization of both originator metoprolol and bisoprolol increased (Table 2 and $1 \mathrm{~A}$ ).

Figure 4 - Volume and procurement prices (CNY) of esmolol injections 2006 to 2012 in the Chongqing District 2006 to 2012

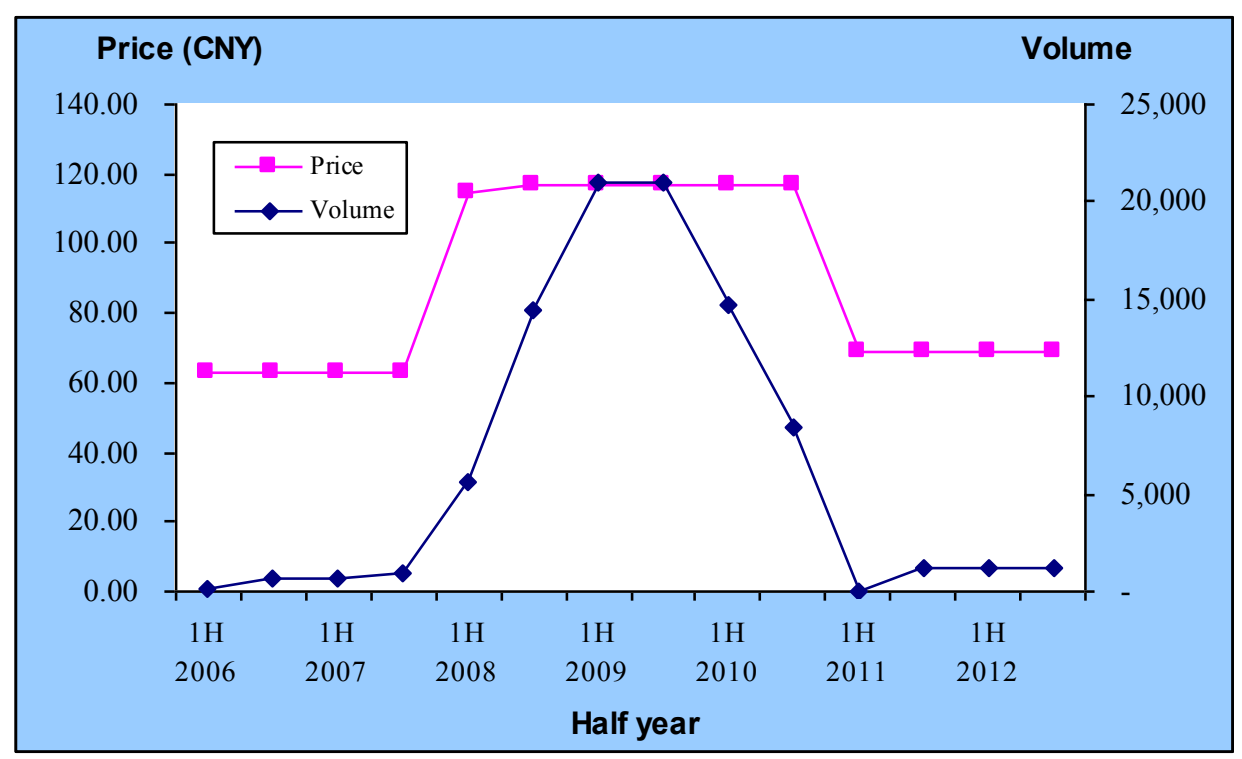

NB Specification of esomol injections were adjusted from $0.1 \mathrm{~g} \times 1 \mathrm{ml}$ to $0.2 \mathrm{~g} \times 2 \mathrm{ml}$ in April 2008

\section{Calcium channel blockers}

There was variable utilisation of generic versus originator calcium channel blockers. Utilisation of amlodipine and felodipine increased whilst utilisation of nifedipine decreased (Tables 2 and $1 \mathrm{~A})$.

There was increasing utilisation of both generic and originator amlodipine besylate $(2.5 \mathrm{mg} \mathrm{x}$ 14 tablets) over time. However, there was no significant difference between the utilisation of either the generic or originator during the study period $(P>0.05)$.

There were generally stable pack prices during this period ((Figure 5 , Tables 3 and $2 \mathrm{~A}$ ). 
Figure 5 - Procurement volume and prices (CNY) of generic besylate amlodipine (2.5mg besylate tablets $\times 14) 2006$ to 2012 in the Chongqing District

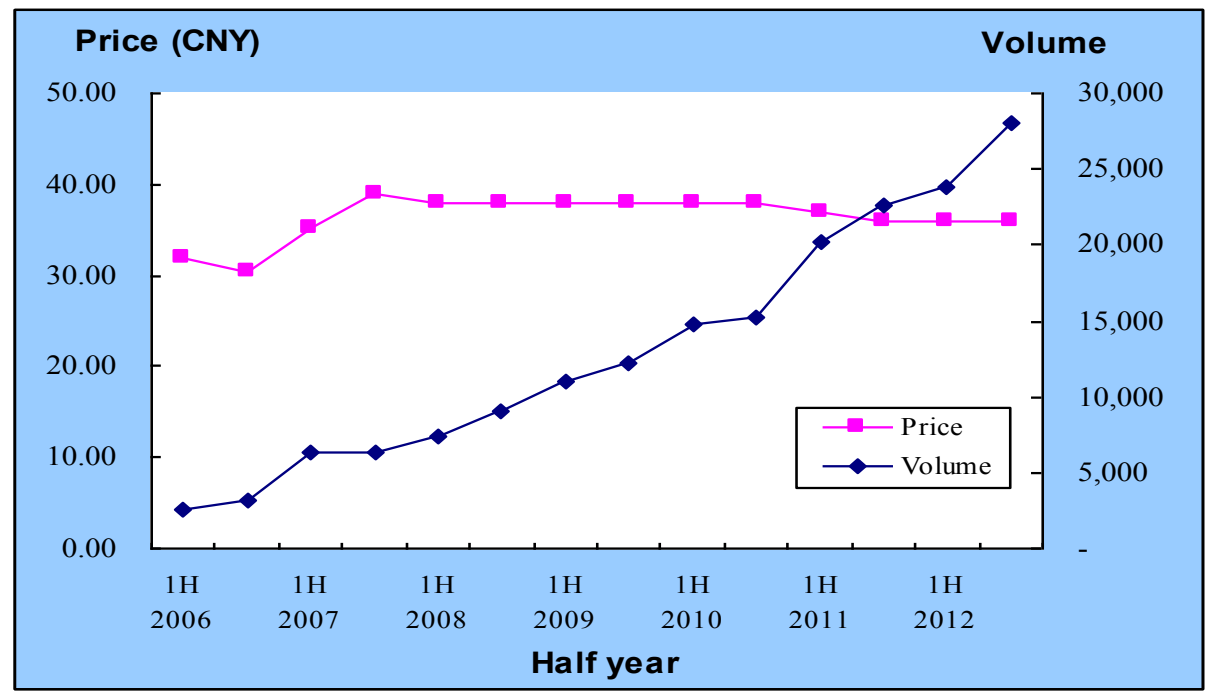

There was decreasing utilisation of generic sustained release tablet nifedipine in the last half of 2012. In the same period, procurement prices decreased (Figure 6). There was a corresponding increase in the consumption of the originator (Tables 2 and $1 \mathrm{~A}$ ). This led to a significant difference in the utilisation of originator vs. generic nifedipine during the course of the study ( $p<0.005$ using the chi-square test).

There was an overall $59 \%$ price differential (expenditure/ unit) for generic nifedipine vs. the originator by the second half of 2012 (Tables 3 and 2A).

Figure 6 - Procured price-volume of sustained release generic nifedipine $20 \mathrm{mg} \times 20$ tablets in the Chongqing District of China 2006 to 2012

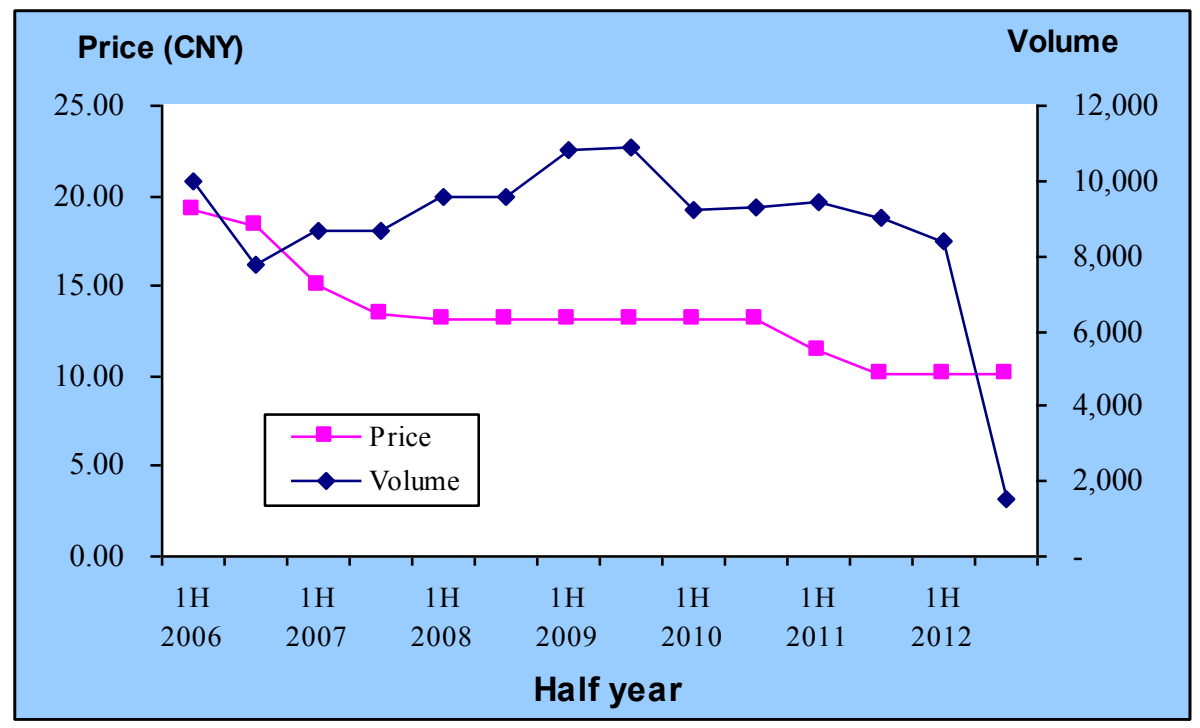




\section{HMG Co-A reductase inhibitors (Statins)}

There was increased utilisation of both generic and originator atorvastatin and simvastatin over time (Tables 2 and $1 \mathrm{~A}$ ). Overall, there was low utilisation of generic vs. originator simvastatin at only $5 \%$ of total units during the past 2.5 years. Expenditure/ unit for generic simvastatin was only $34 \%$ and $25 \%$ originator prices in early 2006 and by the end of 2012 respectively (Table 3 and $2 \mathrm{~A}$ ).

There was high utilisation of generic atorvastatin versus total atorvastatin over time (Tables 2 and $1 \mathrm{~A}$ ) compared with the situation for simvastatin. The procurement price for generic atorvastatin was $47 \%$ of the originator price in the last half of 2012 (Tables 3 and $2 A$ ). The price decline for generic atorvastatin was modest over time and there was no significant difference in the price changes for generic vs. originator atorvastatin between 2006 and 2012 $(p>0.05)$.

\section{Renin-angiotensin inhibiting drugs}

Generally, ARBs were more prescribed than ACEls (Table 2). There was variable utilisation of generic renin-angiotensin inhibiting drugs over time (Tables 2 and $1 \mathrm{~A}$ ). The utilisation of generic irbesartan and telmisartan increased over the study period whilst the utilisation of generic valsartan remained low. Overall, there were no significant difference in the evolution of generic benazepril, irbesartan, and telmisartan versus originators between 2006 and 2012 (Fischer exact test $-p>0.05$ ).

Expenditure/ unit for generic telmisartan and generic valsartan in late 2012 was $41 \%$ and $64 \%$ respectively below early 2006 procurement prices, and expenditure/ unit for generic irbesartan in the second half of 2012 was $41 \%$ below pre-generic procurement prices (Tables 3 and $2 \mathrm{~A}$ ). The procurement price of enalapril maleate tablets moderated at the beginning of 2006 with similar consumption until 2010 (Figure 7). After its procurement price per unit decreased from CNY 22.08 to 13.04, utilisation also decreased. Later one of the manufacturers, Yangtze River Pharmaceuticals, changed its specification from $10 \mathrm{mg} \times 16$ tablets to $10 \mathrm{mg} \times 32$ tablets combined with an increased price (CNY 25.30). The same overall volume was maintained based on the number tablets dispensed although the number of packages decreased. Concurrent with this, another manufacturer (Yabao Pharmaceuticals) lost much of its market share and stopped selling from February 2012. 
Figure 7 - Procurement price-volume of enalapril maleate tablets in the Chongqing District of China 2006 to 2012

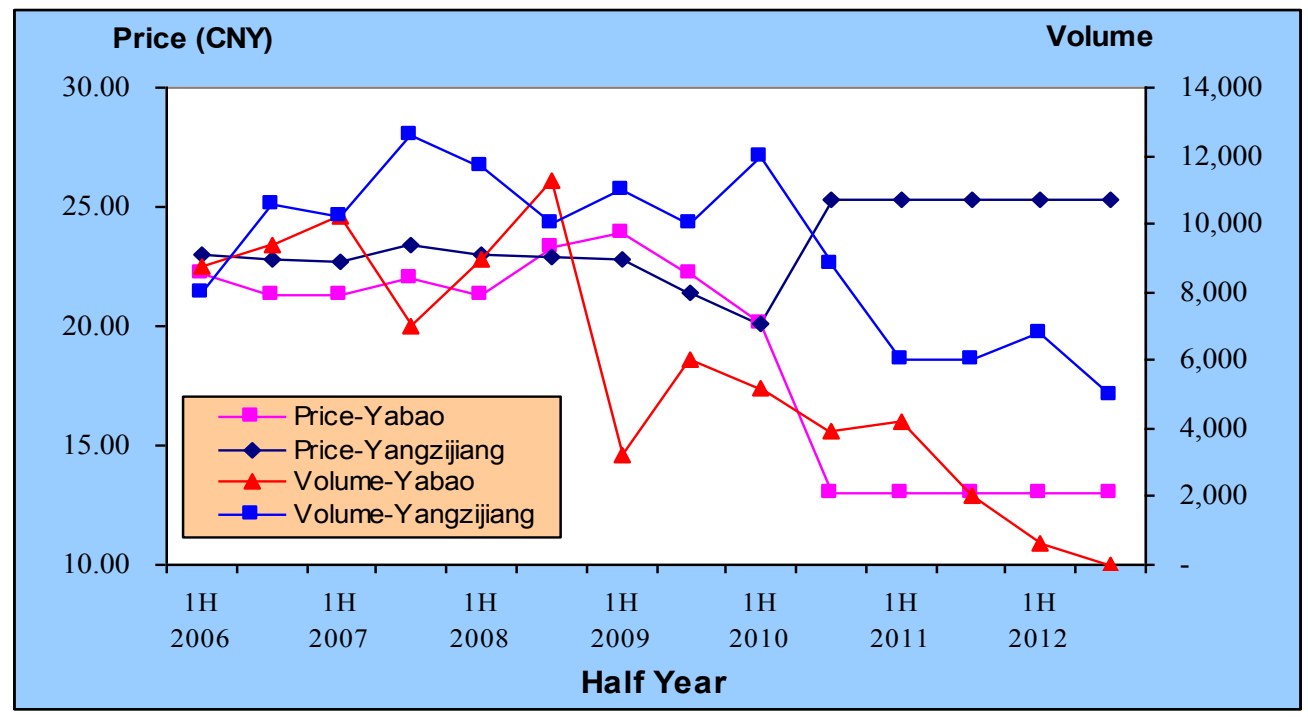

\section{Ligustrazine}

Ligustrazine injection was initially provided by four different manufacturers, and reached a peak of 46,400 bottles in 2007 before falling to 3,600 bottles in the first half of 2011 with procurement terminated in the second half of 2011. The procurement price decreased to CNY 25.70 in the first half of 2009 and has been maintained at this price level (Figure 8).

Figure 8 - Procurement price and volume of ligustrazine injections (CNY) in Chongqing District $\underline{2006 \text { to } 2012}$

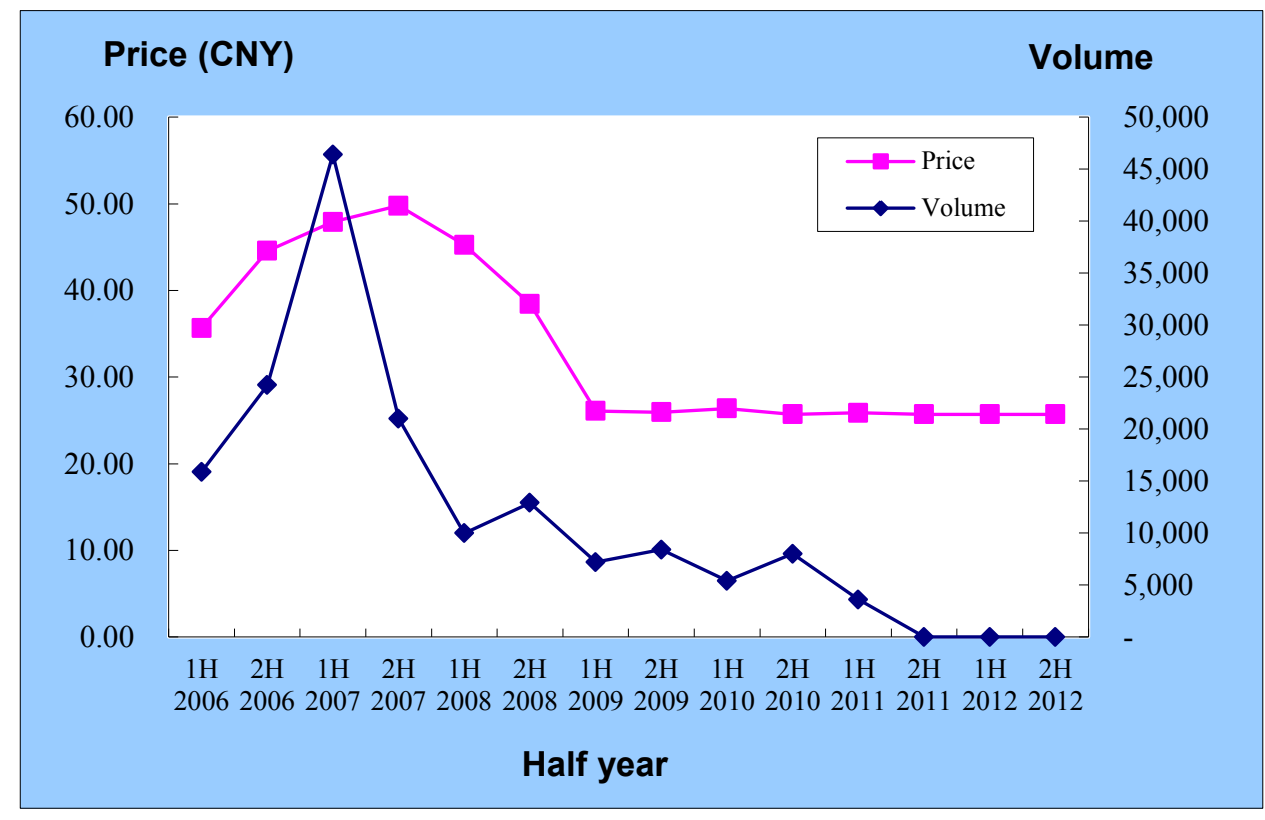




\section{Levocarnitine}

Expenditure on levocarnitine remained high throughout the 7-year period, at more than CNY 2 million a year. The utilisation of levocarnitine powder for injection $(1 \mathrm{~g})$ decreased appreciably after the procurement price almost halved from CNY 40.00 to 20.90 . The price of the second preparation, levocarnitine injection $1 \mathrm{~g} \times 5 \mathrm{ml}$, was only modestly reduced from CNY 51.48 to 46.88 (Figure 9). This injection subsequently increased its utilisation at the expense of the powder plus injection.

Figure 9 - Price-volume of levocarnitine powder $1 \mathrm{~g}$ and levocarnitine injection $1 \mathrm{~g} \times 5 \mathrm{ml}$ (CNY) 2006 to 2012 in the Chongqing District

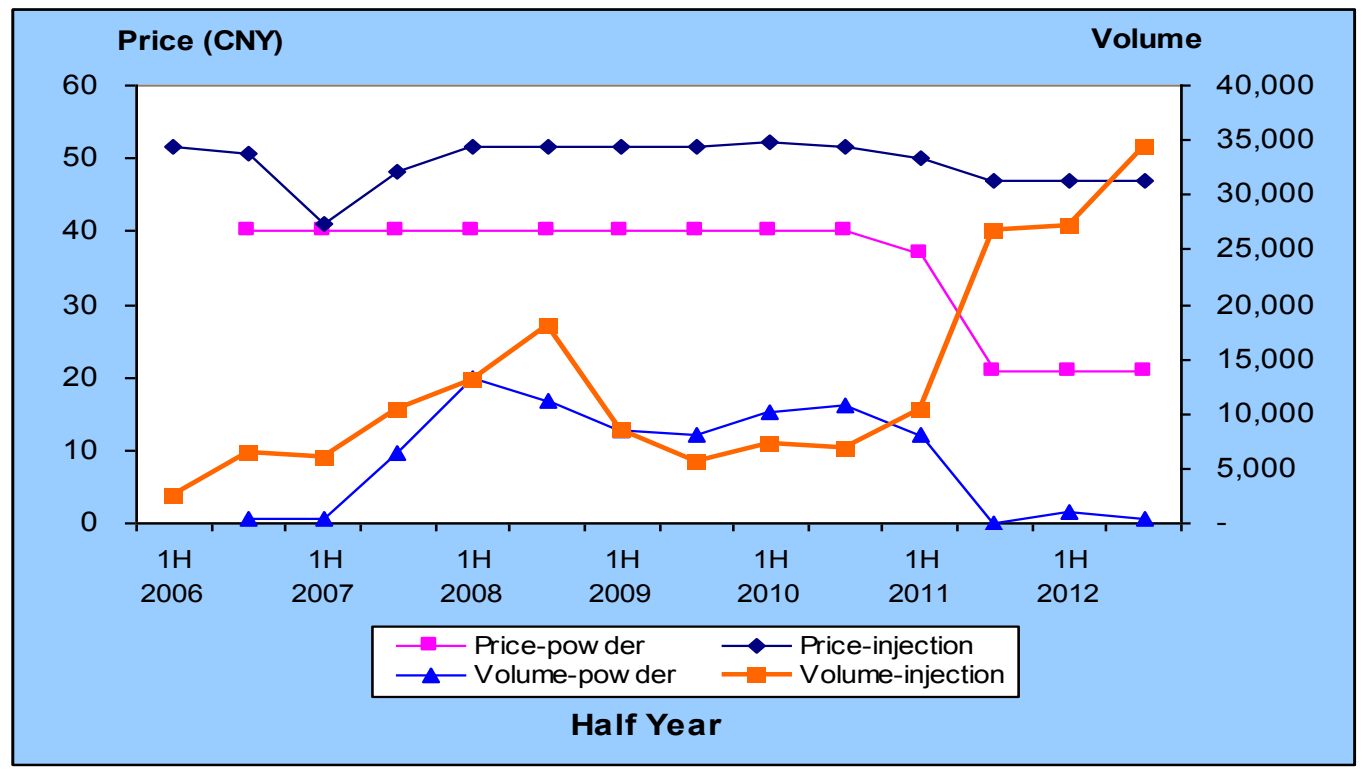

\section{Oxiracetam}

Oxiracetam had the highest utilisation of any cardiovascular or cerebrovascular drug, increasing from 33.4 thousand units in 2006 to 139.6 thousand units in 2012 (Table 1). This was increasingly the injection (Figure 10), which had a higher relative price than the capsules. 


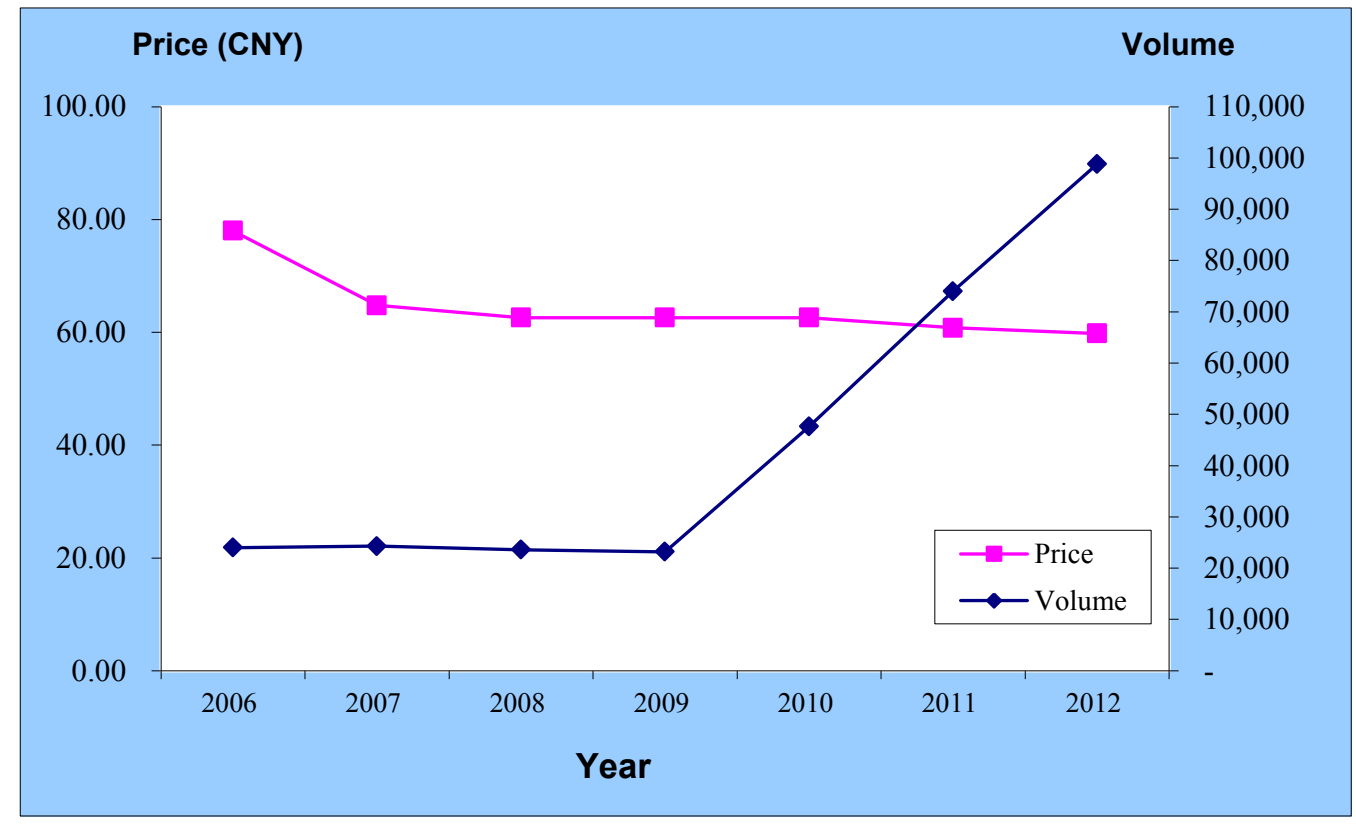

\section{Cinepazide}

There was appreciable fluctuation in the utilisation of cinepazide maleate injection during the study period as a result of neutropenia. This side-effect resulted in some countries refusing market authorisation; alternatively removing it from the market. The WHO also suggested compensating patients for adverse events caused by the drug $[45,46]$. During the study period, its procurement price remained relatively stable

\section{Traditional Chinese medicines}

There was a 4.41 fold increase in the utilisation of traditional Chinese medicines during the study period (Figure 1, Table 1). Three leading preparations currently account for $45 \%$ of the total market share of traditional Chinese medicines with a package price varying from CNY 42.78 to 135.96. High prices appear to be achieved and maintained with limited competition. The rising costs of Chinese materials contributed to these prices, especially at the end of 2009. This resulted in procured expenditure/ unit for traditional Chinese medicines increasing from $23.41 \mathrm{CNY}$ in the 2006 to 41.32 in 2012 , corresponding to a 1.77 fold increase. As a result, procurement costs rose 7.78 fold. Some older products have now been transferred to community pharmacies where prices have fallen

\section{Discussion}

We will initially discuss utilisation and expenditure patterns in the Chongqing District including general findings as well as those for traditional Chinese medicines. Secondly, suggest the implications for the utilisation and expenditure for domestically produced products. Finally, we will suggest potential future reforms that could be considered by the authorities in China. These are based on successful measures among Western European countries, who have 
already achieved equitable and comprehensive healthcare for their citizens. However, we are aware that any future demand-side measures will have only limited success unless the perverse incentives for physicians and hospitals are substantially reduced, e.g. addressing physician salaries who currently earn $5000 \mathrm{CNY}$ (US\$780) a month or less [42].

Firstly, as expected, there was an appreciable increase in the utilisation and expenditure on medicines to treat cardiovascular and cerebrovascular diseases in the Chongqing District of China between 2006 and 2012 (Figures 1 and 2, Table 1). We believe this considerable increase can be attributed to many factors. These include urbanization, an aging population, the expanding scope of medical insurance and improving living standards. However, we are unable to comment further without specific research. This increase though mirrors the considerable increase in utilisation of statins and renin-angiotensin inhibiting drugs seen among Western European countries during the past decade [2-4,6,7,9-11,14-16]

Authorities across countries have generally cut drug prices when faced with higher than expected expenditure or following a financial crisis [47-50]. China is no exception. The main measures introduced by the authorities to try and contain drug expenditure have been price reductions. This has been seen in practice especially for the generics apart from a minority of situations (Tables 3 and $2 \mathrm{~A}$ ), with some price reductions mirroring those among Western European countries $[4,9,15]$. However, price reduction polices implemented in isolation have not been effective in containing overall drug expenditure (Figure 2). These findings are similar to those of other authors in China $[18,31,33]$ as well as other Asian countries. For instance in South Korea, policies concentrating on price controls without addressing demand-side measures did not achieve their desired result $[49,51]$.

Secondly, we believe the considerable growth in the utilisation and expenditure on traditional Chinese medicines (Figures 1 and 2, Table 1) is an important finding. Traditional Chinese medicines accounted for $57 \%$ of total procured expenditure by the end of 2012 . We believe this increase may have been facilitated by the launch of new products with higher prices, relatively limited competition, and the fact that these are typically administered by injection $[29,31,41]$. However, the lack of published data for many of these products, coupled with their high relative prices, suggests continued irrationality in prescribing in China despite the development of essential medicine lists [21].

Concerns with irrationality in prescribing are further endorsed by the continued growth in the utilisation of originator medicines despite generics being available at reduced prices, which can be substantial (Tables 2 and 3, $1 \mathrm{~A}$ and $2 \mathrm{~A}$ ). The reduction in the price of generics over time mirror some of those seen among Western European countries for ARBs and statins [1-5] when compared with earlier originator prices (Tables 3 and 2A). This suggests competition among generic companies has helped reduce procurement prices over time. However, hospitals and authorities will only realise the savings if this price reduction is accompanied by their appreciably increased utilisation where generics are available for procurement. Such activities could be facilitated by enforcement of the Prescription Management Ordinance in 2007 specifying that prescriptions should be written by INN $[18,26]$, especially with recent 
regulations improving the quality of generic medicines in China [21]. High voluntary INN prescribing rates of $98 \%$ to $99 \%$ have been achieved among a range of products and classes in Scotland through a variety of demand-side measures $[2,9,10]$.

Thirdly, we believe based on our findings that there appear to be four different models in operation for domestically produced pharmaceuticals (Table 5).

$\underline{\text { Table } 5 \text { - Four different models for domestically produced pharmaceuticals }}$

\begin{tabular}{|c|c|}
\hline Model & Details \\
\hline 1 & $\begin{array}{l}\text { - A substantial drop in drug prices does appear to affect their subsequent use } \\
\text { - This was illustrated by some products no longer purchased or with limited } \\
\text { procurement after a significant price decline, e.g. generic nifedipine, enalapril of } \\
\text { Yabao Pharmaceuticals, esmolol, levocarnitine powder for injection and } \\
\text { ligustrazine (Figures } 4,6 \text { to } 9 \text { ) } \\
\text { - This was also illustrated by generic simvastatin - where there was limited use } \\
\text { (Tables } 2,1 \mathrm{~A} \text { ) versus the originator. Alongside this, substantial procurement } \\
\text { price reductions ( } 67 \% \text { over the study period) } \\
\text { - The procurement price of the originator simvastatin also reduced over time but } \\
\text { to a lesser extent ( } 29 \% \text { ) (Tables } 3 \text { and } 2 \mathrm{~A} \text { ) } \\
\text { - This may be attributable to the fact that higher prices may translate into higher } \\
\text { profits and conversely lower prices with lower profits, with lower prices } \\
\text { adversely affecting hospital profitability and physician salaries }\end{array}$ \\
\hline 2 & $\begin{array}{l}\text { - A small decrease in the procured price per pack, e.g. } 10 \% \text {, did not appear to } \\
\text { generally change utilisation trends. There may also be an increase } \\
\text { - We believe this was because the whole supply chain including manufacturers } \\
\text { and prescribing doctors could adjust their profitability mix accordingly } \\
\text { - This is illustrated by generic benazepril and telmisartan as well as both } \\
\text { originator and generic atorvastatin with increased utilisation over time despite } \\
\text { limited decreases in procurement expenditure/ unit (Tables } 2 \text { and 3, } 1 \mathrm{~A} \text { and } 2 \mathrm{~A} \text { ) }\end{array}$ \\
\hline 3 & $\begin{array}{l}\text { - Some drugs maintained a relatively high price during the study period and their } \\
\text { consumption substantially increased, e.g. originator metoprolol and bisoprolol } \\
\text { with the procurement price of metoprolol increasing during the study period } \\
\text { (Tables } 2 \text { and } 3,1 \mathrm{~A} \text { and } 2 \mathrm{~A} \text { ) } \\
\text { - This was also seen for oxiracetam } \\
\text { - Other products with a relatively stable price over time also increased their } \\
\text { volume in line with market growth, e.g. amlodipine besylate tablet (Figure 5) } \\
\text { and cinepazide maleate injection (before its severe side effect became broadly } \\
\text { known) }\end{array}$ \\
\hline 4 & $\begin{array}{l}\text { - There appears to be a "CNY } 20 \text { phenomenon", i.e. when the procurement price } \\
\text { per pack drops to near or below CNY 20, utilization rates usually decreased (or } \\
\text { at least stopped increasing) } \\
\text { - Examples include generic nifedipine (Figure 6), generic enalapril and generic } \\
\text { simvastatin }\end{array}$ \\
\hline
\end{tabular}


Consequently, we believe we can speculate on drug utilisation patterns based on these combined findings. Traditional Chinese medicines have generally been preferred first for treatment. This is followed by originators and generics with relatively procurement high prices. One generic medicine in each class typically retains reasonable utilisation, e.g. amlodipine, atorvastatin and irbesartan (Table 2) among the calcium channel blockers, statins and ARBs respectively, although their volume might be lower than the originator. A substantial drop in prices subsequently adversely affects utilisation especially if prices drop to near or below CNY 20 per pack (Table 5$)$.

However, we acknowledge that we will have to perform specific quantitative and qualitative research with defined hypotheses before we can provide specific guidance on drug utilisation patterns alongside changes in expenditure.

With respect to the future, potential measures to enhance patient access to medicines without prohibitive increases in expenditure include enhancing INN prescribing as preciously described. They also include additional measures to further lower the price of generics given some of the low prices seen in Europe $[2,3,7,10]$. Alongside this, there must also be measures to enhance the rational use of medicines, which builds on the essential medicine list concept [21]. This includes encouraging the preferential prescribing of evidenced based low cost and equally effective generics versus more expensive originators. Another potential measure is to restrict prescribing choices within a class. As a result, enhance physician familiarity with the medicines they prescribe. This could potentially reduce adverse drug reactions and drug: drug interactions. This was the philosophy behind the generation of the Wise List in the Stockholm Healthcare Region, which contains approximately 200 drugs including first and second line choices covering most of the therapeutic needs in ambulatory care [52-54]. High adherence rates at 80 to $90 \% \%$ to the voluntary Wise List are enhanced by the involvement of prescribers in the selection process, robust methodologies for selecting the drugs based principally on published evidence of effectiveness and safety, a comprehensive communication programme including a separate Wise List for both patients and physicians, physician trust in the guidance as well as regular feedback [52-55]. Research findings have also shown that increased adherence to the Wise List also reduces costs since medicines that have the most robust data tend to be well established medicines $[52,55,56]$. There are similar examples in Spain and Scotland $[9,10,53]$.

Other initiatives include potentially introducing prescribing quality indicators, which are increasingly used in healthcare as a tool to achieve safe and quality clinical care and cost-effective therapy, as well as for professional learning, remuneration, and accreditation along with financial incentives [56-60]. Any developed indicators must have (a) content validity; (b) face validity, i.e. relevance, credibility \& acceptability (c); concurrent validity - compared with the gold standard (d) construct validity - theoretical construct of quality and (e) predictive validity to be effective and sustainable in practice [61]. 
We are already seeing a reduction in the procurement of traditional Chinese Medicines in the Chongqing District. This will now be monitored, along with the introduction of potential suggestions to further enhance the rational use of medicines. This includes addressing current perverse incentives. As a result, ascertain whether any additional measures are still needed in the future in China to further enhance access to medicines without significantly increasing overall expenditure.

We acknowledge there are some limitations in this research. These include the fact that the utilisation and procurement data was collected from just one leading hospital in one District in China. In addition, we did not use DDDs for the reasons stated. However, we are aware that other authors have not always used DDDs in this type of research. For instance, Hoyle used a market share weighted average price to analyse cost-effectiveness [62], and Danzon and Kim defined standard units as one tablet, one capsule, or one gram, to compare the price of products in different life cycles [63]. Despite these limitations, we believe our findings are robust and transferable across hospitals and drug classes given our choice of hospital and our methodology based on actual procurement data. However, we acknowledge that follow-up studies will be needed in this and other Districts to substantiate some of the findings.

\section{Conclusions}

Traditional Chinese medicines have occupied the largest market share by volume and expenditure in this District, with originators from multinational companies preferred to generics from local manufacturers in view of their relatively higher price. The findings also suggest that price alterations had an appreciable influence on subsequent utilisation patterns, especially when these were significantly decreased. However, further research is needed in this area before we can make any definitive statements. We do believe a number of measures are needed in China to moderate future growth of pharmaceutical expenditure whilst expanding healthcare access. Authorities must seek to enhance the rational use of medicines as well as address some of the barriers. These include addressing the current perverse incentives. This already appears to be happening with a recent reduction in the procurement of traditional Chinese medicines. Suggested measures also include greater encouragement of INN prescribing build on experiences among European countries.

\section{Acknowledgments and conflicts of interest}

We thank the publishing company of the Journal of China Pharmacy for providing us with the datasets used in this study.

Part of the analysis and writing of this paper was supported by a grant from Karolinska Institutet. There are no additional funding sources.

The authors declare that they have no conflicts of interest apart from those stated. No writing assistance was utilized in the production of this manuscript. 


\section{References}

1. Godman B, Haycox A, Schwabe U. Joppi R, Garattini S. Having your cake and eating it: Office of Fair Trading proposal for funding new drugs to benefit patients and innovative companies. Pharmacoeconomics 2008; 26:91-98

2. Godman B, Campbell S, Suh HS, Finlayson A, Bennie M, Gustafsson L. Ongoing measures to enhance prescribing efficiency across Europe: implications for other countries. J Health Tech Assess 2013;1:27-42

3. Godman B, Bennie M, Baumgärtel C, Sović-Brkičić L, Burkhardt T, Fürst J e al. Essential to increase the use of generics in Europe to maintain comprehensive healthcare? Farmeconomia: Health Economics and Therapeutic Pathways 2012, 13 (Suppl 3):5-20

4. Godman B, Shrank W, Andersen M et al. Comparing policies to enhance prescribing efficiency in Europe through increasing generic utilisation: changes seen and global implications. Expert Rev. Pharmacoeconomics Outcomes Res 2010; 10: 707-722

5. Godman B, Wettermark B, Bishop I, et al. European payer initiatives to reduce prescribing costs through use of generics. GaBi J, 2012, 1: 22-27.

6. Godman B, Sakshaug S, Berg C, Wettermark B, Haycox A: Combination of prescribing restrictions and policies to engineer low prices to reduce reimbursement costs. Expert Rev. Pharmacoeconomics Outcomes Res 2011, 11:121-9.

7. van Woerkom M, Piepenbrink H, Godman B, de Metz J, Stephen C, Bennie M, Eimers M, Gustafsson LL. Ongoing measures to enhance the efficiency of prescribing of PPIs and statins in the Netherlands; influence and future implications. Journal of Comparative Effectiveness Research 2012, 1:527-538.

8. Kaplan WA, Ritz LS, Vitello M, Wirta VJ. Policies to promote use of generic medicines in low and middle income countries: A review of published literature, 2000-2010. Health Policy, 2012, 106(3): 211-224.

9. Vončina L, Strizrep T, Godman B et al. Influence of demand-side measures to enhance renin-angiotensin prescribing efficiency in Europe: implications for the future. Expert Rev. Pharmacoecon. Outcomes Res. 11, 469-479 (2011)

10. Godman B, Bishop I, Finlayson A E, et al. Reforms and initiatives in Scotland in recent years to encourage the prescribing of generic drugs, their influence and implications for other countries. Expert review of pharmacoeconomics \& outcomes research, 2013, 13(4): 469-482 11. Godman B, Malmstrom RE, Bennie M, Sakshaug S, Burkhardt et al. Prescribing restrictions - a necessary strategy among some European countries to enhance future prescribing efficiency? Reviews in Health Care 2012; 3: 5-16

12. Bucsics A, Godman B, Burkhardt $T$, et al. Influence of lifting prescribing restrictions for losartan on subsequent sartan utilization patterns in Austria: implications for other countries. Expert review of pharmacoeconomics \& outcomes research, 2012, 12(6): 809-819.

13. Hesse U, Godman B, Petzold M, et al. Impact of Delisting ARBs, Apart from Losartan, on ARB Utilisation Patterns in Denmark: Implications for Other Countries. Applied health economics and health policy, 2013: 1-9.

14. Godman B, Wettermark B, Miranda J, Bennie M, Martin A, Malmström RE. Influence of multiple initiatives in Sweden to enhance ARB prescribing efficiency following generic losartan; 
findings and implications for other countries. International Journal of Clinical Practice 2013, 67: 853-862.

15. Fraeyman J, Van Hal G, Godman B, et al. The potential influence of various initiatives to improve rational prescribing for proton pump inhibitors and statins in Belgium. Expert review of pharmacoeconomics \& outcomes research, 2013, 13(1): 141-151.

16. Martin A, Godman B, Miranda J, Tilstone J, Saleem N. Olsson E, Acosta A et al. Measures to improve angiotensin receptor blocker prescribing efficiency in the UK: findings and implications. Jn Comparative Effect Res 2014; 3(1): 41-51

17. Moon J, Flett A, Godman B et al. Getting better value from the NHS drug budget. BMJ 2011; 342: 30-32

18. Zeng W. A price and use comparison of generic versus originator cardiovascular medicines: a hospital study in Chongqing, China. BMC Health Services Research 2013 13:390.

19. Meng $Q$, Xu L, Zhang $Y$, et al. Trends in access to health services and financial protection in China between 2003 and 2011: a cross-sectional study. The Lancet, 2012, 379(9818): 805-814.

20. Barber S, Yao L. Development and status of health insurance systems in China. Int J Health Plann Mgmt 2011; 26: 339-356

21. Barber S, Huang B, Santoso B, Laing R, Paris V, Wu C. The reform of the essential medicines system in China: a comprehensive approach to universal coverage. J Glob Health. 2013 June; 3(1): 010303

22. Li X, Zhang W. The impacts of health insurance on health care utilization among the older people in China. Social Science \& Medicine, 2013.85:59-65

23. Sun J. International experiences of promoting generics use and its implications to China. Journal of Evidence-Based Medicine, 2013, 6(2): 74-80.

24. Li L. The challenges of healthcare reforms in China. P u b I i c Health 125 ( 2011 ) 6e8

25. Ling R, Liu F, Lu X, Wang W. Emerging issues in public health: A perspective on China's healthcare system. Pu b I i c He a I t h 125 ( 20101 ) 9 e1 4

26. Sun, Q., Santoro, M. A., Meng, Q., Liu, C., \& Eggleston, K. (2008). Pharmaceutical policy in China. Health Affairs, 27(4), 1042-1050.

27. Yu X, Li C, Shi Y, Yu M: Pharmaceutical supply chain in China: Current issues and implications for health system reform. Health Policy 2010, 97: 8-15

28. Wagstaff $A$, Lindelow $M$. Can insurance increase financial risk? The curious case of health insurance in China. J Health Econ. 2008 Jul;27(4):990-1005

29. Mao W, Tang S, Chen W. Does perverse economic incentive lead to the irrational uses of medicines? Expert Rev. Pharmacoecon. Outcomes Res. 13(6), 693-696 (2013)

30. Liu L, Lu Z, Zhang X. Analysis of Rational use of Drugs in Community Health Service Facilities. Chinese Health Econ. 2009; 28(4): 45-7

31. Reynolds L, McKee M. Serve the people or close the sale? Profit-driven overuse of injections and infusions in China's market-based healthcare system. Int J Health Plann Mgmt 2011; 26: 449-470

32. Reynolds L, McKee M: Factors influencing antibiotic prescribing in China: An exploratory analysis. Health Policy 2009, 90: 32-36. 
33. Lu C, Ross-Degnan D, Stephens P, Liu B, Wagner A. Changes in use of antidiabetic medications following price regulations in China (1999-2009). JPHSR 2013, 4: 3-11

34. Meng Q, Cheng G, Silver L, Sun X, Rehnberg C, Tomsom G: The impact of China's retail drug price control policy on hospital expenditures: a case study in two Shandong hospitals. Health Policy Plan 2005, 20: 185-196.

35. Chen Y, Schweitzer SO: Issues in Drug Pricing, Reimbursement, and Access in China with References to Other Asia-Pacific Region. Value in Health 2008, 11:124-129.

36. Lim D, Emery J, Lewis J, Sunderland VB: A systematic review of the literature comparing the practices of dispensing and non-dispensing doctors. Health Policy 2009, 92: 1-9.

37. Jin SR, Hu L, Du L, Huang K: Analysis of drug use in 29 hospitals of Chongqing area from 2008 to 2010. China Pharmacy 2012, 23: 872-876.

38. Qu C, Xie H, Zhang P, Shi W: Dynamic analysis of drugs administration in some hospitals in Guangdong area during the period 2002-2005. China Pharmacy 2006, 17: 1072-1074.

39. Teng L, Xin HW, Blix HS, Tsutani K. Review of the use of defined daily dose concept in drug utilisation research in China. Pharmacoepidemiol Drug Saf. 2012 Oct;21(10):1118-24 40. Ji K, Chen J, et al. Comments on serious anaphylaxis caused by nine Chinese herbal injections used to treat common colds and upper respiratory tract infections. Regul Toxicol Pharmacol 2009; 55(2): 134-138

41. Tao T, Xu C, Hu M, Liao W, Jiang X: Analysis of Chinese pharmaceutical price policy from 1997 to 2011. Chin J Health Policy 2011, 4:46-52

42. Jingang A. Which future for doctors in China? The Lancet 2013; 382: 936-7

43. Grimshaw J, Campbell M, Eccles $M$ et al. Experimental and quasi-experimental designs for evaluating guidelines implementation strategies. Family Practice 17, S11-S16 (2000)

44. WHO: Guidelines for ATC classification and DDD assignment. In Oslo: WHO Collaborating Centre for Drug Statistics Methodology. www.whocc.no

45. United Nations. Consolidated list of products whose consumption and/ or sale have been banned, withdrawn, severely restricted or not approved by governments [M ]. 8th ed. New York: United Nations Publication, 2003:58

46. Yi Z, Liu F, Zhang J, Li Xi, Zhai S. Cinepazide-induced hematological adverse reactions: review and analysis. Adverse Drug Reactions Journal 2010, 12(4):251-254. (in Chinese) 47. Vogler S, Zimmermann N, Leopold C, de Joncheere K. Pharmaceutical policies in European countries in response to the global financial crisis. South Med Rev. 2011; 4(2): $69-79$

48. Sermet C, Andrieu V, Godman B et al Van Ganse E. Ongoing pharmaceutical reforms in France; implications for key stakeholder groups. Applied Health Economics and Health Policy 2010; 8: 7-24

49. Kwon H Y, Hong J M, Godman B et al. Price cuts and drug spending in South Korea: The case of antihyperlipidemic agents. Health Policy 112 (2013) 217- 226

50. Lee I H, Bloor K, Hewitt C, et al. The effects of new pricing and copayment schemes for pharmaceuticals in South Korea. Health Policy, 2012, 104(1): 40-49.

51. Kwon HY, Yang BM. Do generics really create savings on drug expenditures? Korean J. Health Econ. Policy 17(4), 23-42 (2011).

52. Gustafsson LL, Wettermark B, Godman B et al. The "Wise List"- A comprehensive concept to select, communicate and achieve adherence to recommendations of essential 
drugs in ambulatory care in Stockholm. Basic \& Clinical Pharmacology \& Toxicology 2011; 108:224-233 (also 15)

53. Björkhem-Bergman J, Andersen-Karlsson E, Laing $\mathrm{R}$ et al. Interface management of pharmacotherapy. Joint hospital and primary care drug recommendations. Eur J Clin Pharmacol 2013; 69 (Suppl 1):S73-S78

54. da Costa Lima-Dellamora E, Caetano R, Gustafsson LL et al. An Analytical Framework for Assessing Drug and Therapeutics Committee Structure and Work Processes in Tertiary Brazilian Hospitals. Basic Clin Pharmacol Toxicol. 2014 Feb 14. doi: 10.1111/bcpt.12215. [Epub ahead of print]

55. Godman B, Wettermark B, Hoffman M et al. Multifaceted national and regional drug reforms and initiatives in ambulatory care in Sweden; global relevance. Expert Rev Pharmacoeconomcis Outcomes Research 2009; 9:65-83

56. Norman $\mathrm{C}$, Zarrinkoub R, Hasselström $\mathrm{J}$ et al. Potential savings without compromising the quality of care. Int J Clin Pract 2009: 63:1320-26

57. Wettermark B, Jacobsson B, Godman B, Haaijer-Ruskamp F. Soft regulations in pharmaceutical policymaking - an overview of current approaches and their consequences. Appl Health Econ Health Policy 2009;7:1-11

58. Hoven JL, Haaijer-Ruskamp FM, Vander Stichele RH; DURQUIM Scientific Committee. Indicators of prescribing quality in drug utilization research: report of a European meeting (DURQUIM, 13-15 May 2004). Eur J Clin Pharmacol 2005;60:831-4

59. Campbell $\mathrm{SM}_{2}$ Reeves D, Kontopantelis E, Sibbald B, Roland M. Impact of pay-for-performance on quality of English primary care: interrupted time series analysis. N Eng J Med 2009: 361: 368-378

60. Wettermark B, Pehrsson $\AA$, Juhasz-Haverinen $M$ et al. Financial incentives linked to self-assessment of prescribing patterns - a new approach for quality improvement of drug prescribing in primary care. Quality in Primary Care 2009;17:179-89

61. Godman B, Paterson K, Malmstrom R et al. Improving the managed entry of new medicines: sharing experiences across Europe. Expert Review Pharmacoeconomics and Outcomes Res 2012; 12: 439-41

62. Hoyle M: Future drug prices and cost-effectiveness analyses. Pharmacoeconomics 2008, 26:589-602.

63. Danzon PM, Kim JD: The life cycle of pharmaceuticals: a cross-national perspective. London: Office of Health Economics, 2002 [online]. Available from URL: http://www.opengrey.eu/item/display/10068/553731 [Accessed 2013 December 24] 


\section{Appendix}

Table $1 \mathrm{~A}$ - Utilisation of both generics and originators for 12 single cardiovascular products in the Chongqing District between 2006 to 2012

\begin{tabular}{|c|c|c|c|c|c|c|c|c|c|c|c|c|c|c|}
\hline Product & 1H 2006 & $2 \mathrm{H} 2006$ & 1H 2007 & 2H 2007 & 1H 2008 & 2H 2008 & 1H 2009 & 2H 2009 & 1H 2010 & $2 \mathrm{H} 2010$ & 1H 2011 & 2H 2011 & 1H 2012 & 2H 2012 \\
\hline \multicolumn{15}{|l|}{\begin{tabular}{|l} 
Beta Blockers \\
\end{tabular}} \\
\hline Metoprolol - Generic & 0 & 0 & 0 & 0 & 0 & 0 & 0 & 0 & 0 & 0 & 0 & 0 & 0 & 0 \\
\hline *Metoprolol - Originator & 9660 & 12977 & 13251 & 15051 & 17040 & 16640 & 18000 & 19920 & 22800 & 23280 & 26710 & 37440 & 51840 & 50400 \\
\hline Bisoprolol-Generic & 0 & 0 & 0 & 0 & 0 & 0 & 0 & 0 & 0 & 0 & 0 & 0 & 0 & 0 \\
\hline Bisoprolol - Originator & 4020 & 4380 & 7200 & 6840 & 8460 & 9840 & 7200 & 10405 & 15480 & 18900 & 19260 & 17460 & 20880 & 19980 \\
\hline \begin{tabular}{|l|} 
Total beta blockers \\
\end{tabular} & 13680 & 17357 & 20451 & 21891 & 25500 & 26480 & 25200 & 30325 & 38280 & 42180 & 45970 & 54900 & 72720 & 70380 \\
\hline \multicolumn{15}{|l|}{ Calcium Channel blockers } \\
\hline **Amlodipine-Generic & 4245 & 5200 & 8600 & 8570 & 9400 & 11800 & 15210 & 18940 & 23900 & 23670 & 30708 & 29900 & 31440 & 35070 \\
\hline Amlodipine - Originator & 5100 & 2800 & 4500 & 4400 & 4200 & 5400 & 7866 & 11600 & 12000 & 14200 & 14900 & 10800 & 15600 & 26250 \\
\hline Nifedipine-Generic & 13509 & 11750 & 12767 & 13361 & 14600 & 13900 & 14600 & 13830 & 13900 & 13200 & 14400 & 15200 & 13800 & 3300 \\
\hline Nifedipine - originator & 5400 & 6480 & 9120 & 9530 & 19201 & 12420 & 15390 & 9990 & 21240 & 18090 & 18540 & 18630 & 27000 & 28620 \\
\hline Felodipine - Generic & 8 & 240 & 340 & 780 & 280 & 800 & 550 & 500 & 450 & 490 & 50 & 200 & 340 & 900 \\
\hline Felodipine-Originator & 2160 & 480 & 2400 & 4270 & 6317 & 6240 & 9600 & 10080 & 16464 & 13380 & 16960 & 19200 & 28560 & 24720 \\
\hline Total calcium channel blockers & 30422 & 26950 & 37727 & 40911 & 53998 & 50560 & 63216 & 64940 & 87954 & 83030 & 95558 & 93930 & 116740 & 118860 \\
\hline \begin{tabular}{|l} 
Total generics \\
\end{tabular} & 17762 & 17190 & 21707 & 22711 & 24280 & 26500 & 30360 & 33270 & 38250 & 37360 & 45158 & 45300 & 45580 & 39270 \\
\hline$\%$ generics & 58 & 64 & 58 & 56 & 45 & 52 & 48 & 51 & 43 & 45 & 47 & 48 & 39 & 33 \\
\hline \multicolumn{15}{|l|}{ Renin-angiotensin inhibitors } \\
\hline Benazepril-Generic & & & & 329 & 1080 & 650 & 200 & 3180 & 7480 & 7330 & 6240 & 6700 & 8160 & 7440 \\
\hline \begin{tabular}{|l|} 
Benazepril - Originator \\
\end{tabular} & 3600 & 2880 & 3520 & 5040 & 3600 & 7680 & 7560 & 9000 & 8640 & 9000 & 11460 & 13560 & 14700 & 16199 \\
\hline Irbesartan-Generic & & & & 700 & 4300 & 7000 & 8600 & 10000 & 15565 & 10170 & 8000 & 11800 & 11000 & 14000 \\
\hline Irbesartan-Originator & 3050 & 3600 & 6700 & 4800 & 7156 & 5530 & 7880 & 12640 & 15120 & 17800 & 16920 & 17280 & 21960 & 21240 \\
\hline Losartan-Generic & & & & & & & & & & & & & 1400 & 3200 \\
\hline \begin{tabular}{|l} 
Losartan-Originator \\
\end{tabular} & 2760 & 3400 & 5000 & 5990 & 8000 & 9800 & 14500 & 8830 & 21800 & 16800 & 14600 & 21600 & 20800 & 16820 \\
\hline Telmisartan-Generic & 252 & & 150 & 1350 & 2753 & 2559 & 2800 & 2800 & 3600 & 4000 & 5000 & 4800 & 5575 & 5600 \\
\hline Telmisartan-Originator & 982 & 600 & 1150 & 2437 & 4000 & 4400 & 5530 & 3400 & 6700 & 4900 & 5448 & 9400 & 14200 & 12000 \\
\hline Valsartan-Generic & 614 & 200 & 500 & 700 & & 400 & 450 & 600 & 750 & 450 & 800 & 500 & 775 & 950 \\
\hline Valsartan- Originator & 600 & 1166 & 540 & 3710 & 6744 & 7665 & 9450 & 11580 & 11520 & 12480 & 17060 & 23080 & 28800 & 30080 \\
\hline Total renin-angiotensin inhibitors & 11858 & 11846 & 17560 & 25056 & 37633 & 45684 & 56970 & 62030 & 91175 & 82930 & 85528 & 108720 & 127370 & 127529 \\
\hline Total generics & 866 & 200 & 650 & 3079 & 8133 & 10609 & 12050 & 16580 & 27395 & 21950 & 20040 & 23800 & 26910 & 31190 \\
\hline$\%$ generics (all) & 7 & 2 & 4 & 12 & 22 & 23 & 21 & 27 & 30 & 26 & 23 & 22 & 21 & 24 \\
\hline$\%$ generic benazapril vs. all benazepril & & & & 6 & 23 & 8 & 3 & 26 & 46 & 45 & 35 & 33 & 36 & 31 \\
\hline$\%$ generic irbesartan vs all irbesartan & 0 & 0 & 0 & 13 & 38 & 56 & 52 & 44 & 51 & 36 & 32 & 41 & 33 & 40 \\
\hline$\%$ generic telmisartan & 20 & 0 & 12 & 36 & 41 & 37 & 34 & 45 & 35 & 45 & 48 & 34 & 28 & 32 \\
\hline \multicolumn{15}{|l|}{ Statins } \\
\hline ***Atorvastatin - Generic & 3840 & 3840 & 4080 & 4320 & 4460 & 4498 & 5040 & 6720 & 11039 & 16620 & 24480 & 33040 & 40010 & 49783 \\
\hline Atorvastatin - Originator & 720 & 1200 & 1680 & 840 & 2455 & 2884 & 8200 & 12600 & 13920 & 17520 & 17760 & 16400 & 17520 & 24762 \\
\hline Simvastatin-Generic & 268 & 116 & 96 & 300 & 912 & 1140 & 2736 & 1980 & 2640 & 1780 & 1760 & 1440 & 960 & 720 \\
\hline Simvastatin - Originator & 1950 & 5260 & 7805 & 7799 & 15600 & 15800 & 15800 & 18520 & 31200 & 32600 & 31600 & 29200 & 20000 & 18600 \\
\hline Total Statins & 6778 & 10416 & 13661 & 13259 & 23427 & 24322 & 31776 & 39820 & 58799 & 68520 & 75600 & 80080 & 78490 & 93865 \\
\hline Total generics & 4108 & 3956 & 4176 & 4620 & 5372 & 5638 & 7776 & 8700 & 13679 & 18400 & 26240 & 34480 & 40970 & 50503 \\
\hline$\%$ generics & 61 & 38 & 31 & 35 & 23 & 23 & 24 & 22 & 23 & 27 & 35 & 43 & 52 & 54 \\
\hline Total all products & 62738 & 66569 & 89399 & 101117 & 140558 & 147046 & 177162 & 197115 & 276208 & 276660 & 302656 & 337630 & 395320 & 410634 \\
\hline Total generics & 22736 & 21346 & 26533 & 30410 & 37785 & 42747 & 50186 & 58550 & 79324 & 77710 & 91438 & 103580 & 113460 & 120963 \\
\hline$\%$ generics & 36 & 32 & 30 & 30 & 27 & 29 & 28 & 30 & 29 & 28 & 30 & 31 & 29 & 29 \\
\hline
\end{tabular}

NB. Utilisation measured in package units, ${ }^{*}=2$ Specifications; ${ }^{* *}=$ several manufacturers and specifications. ${ }^{* * *}=$ Different specification to the originator. $1 \mathrm{H}=$ first half of the year; $2 \mathrm{H}=$ second half of the year 
Table 2A - Change in procurement expenditure/ unit (CNY) for 12 single originator and generic cardiovascular and cerebrovascular drugs in the Chongqing District between 2006 and 2012

\begin{tabular}{|c|c|c|c|c|c|c|c|c|c|c|c|c|c|c|c|c|c|}
\hline Product & $1 \mathrm{H} 2006$ & $2 \mathrm{H} 2006$ & $1 \mathrm{H} 2007$ & $2 \mathrm{H} 2007$ & 1H 2008 & $2 \mathrm{H} 2008$ & 1H 2009 & $2 \mathrm{H} 2009$ & $1 \mathrm{H} 2010$ & $2 \mathrm{H} 2010$ & 1H 2011 & $2 \mathrm{H} 2011$ & 1H 2012 & $2 \mathrm{H} 2012$ & $\%$ change & $\begin{array}{c}2 \mathrm{2H} 2012 \% \text { vs. pre- } \\
\text { originator loss } \\
\text { prices }\end{array}$ & $\begin{array}{c}\% \text { difference generic } \\
2 \mathrm{H} 2012 \text { generic vs. } \\
\text { originator } 1 \mathrm{H} 2006 \\
\end{array}$ \\
\hline${ }^{*}$ Metoprolol - Originator & 10.02 & 8.59 & 8.67 & 9.51 & 8.68 & 9.02 & 9.22 & 9.60 & 9.70 & 9.63 & 12.72 & 12.92 & 13.92 & 13.78 & 37 & & \\
\hline Bisoprolol - Originator & 32.35 & 30.90 & 30.90 & 30.91 & 30.91 & 30.91 & 30.91 & 30.91 & 30.91 & 30.91 & 30.63 & 30.43 & 30.40 & 30.40 & -6 & & \\
\hline **Amlodipine-Generic & 32.77 & 31.46 & 34.56 & 37.40 & 36.94 & 36.98 & 37.21 & 38.44 & 39.11 & 38.20 & 38.32 & 38.37 & 38.19 & 39.10 & 19 & & 0 \\
\hline Amlodipine-Originator & 39.03 & 37.17 & 36.83 & 39.29 & 36.78 & 36.78 & 36.77 & 36.76 & 36.78 & \begin{tabular}{|l|}
36.03 \\
\end{tabular} & 33.73 & 33.13 & 33.13 & 32.81 & -16 & & \\
\hline Nifedipine-Generic & 19.31 & 18.18 & 15.85 & 14.27 & 14.43 & 13.69 & \begin{tabular}{ll|l}
14.38 \\
\end{tabular} & 14.10 & 14.74 & \begin{tabular}{|l|}
14.61 \\
\end{tabular} & 13.58 & 12.84 & 12.91 & 12.84 & -34 & & -64 \\
\hline Nifedipine-originator & 35.45 & 33.50 & 33.50 & 34.51 & 33.50 & 33.50 & 33.50 & 33.50 & 33.50 & 33.45 & 31.38 & 31.13 & 31.13 & 31.13 & -12 & & \\
\hline Felodipine-Generic & 14.68 & 25.80 & 25.80 & 25.88 & 25.39 & 25.39 & 25.39 & 25.39 & 25.39 & 25.39 & 25.39 & 29.04 & 35.29 & 35.29 & 140 & & -3.4 \\
\hline Felodipine-Originator & 36.55 & 34.20 & 34.20 & 34.78 & 34.20 & 34.11 & 34.07 & 34.20 & 33.99 & \begin{tabular}{|l|}
33.54 \\
\end{tabular} & 33.12 & 32.31 & 32.50 & 32.50 & -11 & & \\
\hline Benazepril-Generic & & & & 35.70 & 35.70 & 35.70 & 35.70 & 35.70 & 35.70 & 35.70 & 32.21 & 29.22 & 29.22 & 29.22 & -18 & -38 & \\
\hline Benazepril - Originator & 48.05 & 46.83 & 46.83 & 46.83 & 46.83 & 46.83 & 46.83 & 46.83 & 46.83 & 46.83 & \begin{tabular}{|l|}
45.16 \\
\end{tabular} & 44.00 & 44.00 & 43.30 & -10 & & \\
\hline Irbesartan-Generic & & & & 22.96 & 22.95 & 22.95 & 22.95 & 22.95 & 22.95 & 22.95 & 20.65 & 18.34 & 18.34 & 18.34 & & -41 & \\
\hline Irbesartan-Originator & 32.73 & 31.26 & 31.26 & 31.65 & 31.26 & 31.26 & 31.26 & 31.26 & 31.26 & 31.26 & 31.26 & 31.26 & 31. & 31. & & & \\
\hline Losartan-Generic & & & & & & & & & & & & & 66.08 & 66.08 & 0 & 42 & \\
\hline Losartan-Originator & 49.29 & 48.34 & 48.44 & 49.85 & 48.25 & 48.32 & 49.30 & 48.89 & 49.72 & \begin{tabular}{|l|l|}
47.78 \\
\end{tabular} & 45.93 & 46.63 & 45.93 & 50.11 & 2 & & \\
\hline Telmisartan-Generic & 22.67 & & 35.22 & 36.00 & 35.22 & 35.22 & 35.22 & 35.22 & 35.22 & 35.22 & 28.11 & 20.53 & 20.71 & 20.71 & -9 & & -41 \\
\hline Telmisartan-Originator & 35.02 & 34.15 & 34.15 & 34.15 & 34.15 & 34.15 & 34.15 & 34.15 & 34.15 & 34.15 & 34.15 & 34.15 & 34.15 & 34.15 & -2 & & \\
\hline Valsartan-Generic & 20.69 & 19.84 & 19.84 & 19.84 & & \begin{tabular}{ll|}
19.84 \\
\end{tabular} & 19.84 & 19.84 & 19.84 & \begin{tabular}{|l|l|}
19.84 \\
\end{tabular} & 17.44 & 16.00 & 16.00 & 16.00 & -23 & & -64 \\
\hline Valsartan-Originator & 44.60 & 43.28 & 42.78 & 43.75 & 42.78 & 42.78 & 42.78 & 42.78 & 42.78 & 42.78 & 41.10 & 39.75 & 39.60 & 38.61 & -13 & & \\
\hline${ }^{* * *}$ Atorvastatin -Generic & 35.09 & 33.21 & 31.00 & 30.59 & 30.09 & 30.09 & 30.09 & 30.09 & 30.09 & 31.90 & 30.14 & 28.05 & 28.92 & 29.00 & -17 & & -57 \\
\hline Atorvastatin-Originator & 67.72 & 67.00 & 67.00 & 67.00 & 67.00 & 67.02 & 67.00 & 67.00 & 67.00 & 67.00 & 66.67 & 62.24 & 62.24 & 62.24 & -8 & & \\
\hline Simvastatin-Generic & 28.07 & 27.54 & 25.81 & 24.67 & 24.09 & 24.09 & 24.09 & 23.52 & 21.74 & 19.57 & 13.74 & 13.74 & 13.74 & 9.32 & -67 & & -82 \\
\hline Simvastatin-Originator & 51.82 & 50.30 & 50.30 & 51.07 & 50.30 & 50.30 & 50.30 & 50.30 & 26.70 & 26.67 & 26.62 & 36.53 & 36.81 & 36.81 & -29 & & \\
\hline
\end{tabular}

NB. ${ }^{*}=2$ Specifications; ${ }^{* *}=$ several manufacturers and specifications. ${ }^{* * *}=$ Different specification to the originator. $1 \mathrm{H}=$ first half of the year; $2 \mathrm{H}=$ second half of the year 